\title{
As tecnologias digitais e as relações interpessoais no cotidiano das instituições educativas
}

\author{
Digital technologies and interpersonal relations in the daily life \\ of educational institutions
}

\section{Editor}

Alexandre Anselmo Guilherme PUCRS, RS, Brasil

\section{Editor Assistente}

Cibele Cheron

PUCRS, RS, Brasil

\section{Editores Associados}

Bruno Antonio Picoli

Universidade Federal da Fronteira Sul, Chapecó, SC, Brasil

Pricila Kohls dos Santos

Universidade Católica de Brasília,

Brasília, DF, Brasil

Renato de Oliveira Brito

Universidade Católica de Brasilia,

Brasilia, DF, Brasil

Elisa Ustarroz

PUCRS, Porto Alegre, RS, Brasil

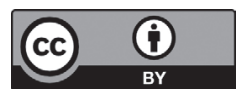

\section{RESUMO}

Observa-se o crescente uso das tecnologias digitais por pessoas de diferentes idades e em diversos contextos. No cotidiano das instituições educativas, da educação básica ao ensino superior, as ferramentas digitais podem auxiliar o professor a promover uma aula mais significativa e interativa, assim como podem facilitar as relações interpessoais, promovendo espaços além da sala de aula. Este estudo tem por objetivo analisar a produção científica sobre o uso das tecnologias e o desenvolvimento das relações interpessoais no cotidiano das instituições educativas em pesquisas produzidas no Brasil entre o período de 2015 a 2019. A metodologia utilizada se refere aos princípios de estado de conhecimento e tem como fonte principal a Biblioteca Digital Brasileira de Teses e Dissertações (BDTD). O corpus de análise constituiu-se por doze (12) dissertações e seis (6) teses, totalizando 18 produções. A partir da análise da bibliografia foram levantadas três categorias: uso das tecnologias digitais na aprendizagem dos estudantes; impacto das tecnologias digitais no cotidiano dos estudantes; e formação de professores no cotidiano das instituições educativas. Os resultados apontam que as tecnologias digitais estão presentes desde muito cedo na vida de crianças e jovens, impactando nas suas relações interpessoais e na forma de verem o mundo. Foi possível compreender que a unidade educativa deve aproveitar as vantagens e as potencialidades das tecnologias digitais, visando favorecer o desenvolvimento de aprendizagens significativas aos estudantes do século XXI, preparando-os para atuarem no mundo que os rodeia de maneira saudável e responsável.

Palavras-chave: Educação. Cotidiano. Tecnologias digitais. Relações interpessoais.

\section{ABSTRACT}

There is a growing use of digital technologies by people of different ages and in various contexts. In the daily life of educational institutions, from basic to higher education, digital tools can help teachers to promote a more meaningful and interactive class, as well as facilitate interpersonal relationships, promoting spaces beyond the 
classroom. This study aims to analyze the scientific production on the use of technologies and the development of interpersonal relations in the daily life of educational institutions in research produced in Brazil, from 2015 to 2019. The methodology used refers to the principles of state of knowledge and its main source is the Brazilian Digital Library of Theses and Dissertations - BDTD. The corpus of analysis consisted of twelve (12) master dissertations and six (6) doctoral theses, totaling 18 scientific productions. From the analysis of the bibliography three categories were raised: use of digital technologies in student learning; impact of digital technologies on students' daily lives; teacher training in the daily life of educational institutions. The results show that digital technologies are present very early in the lives of children and young people, impacting their interpersonal relationships and the way they see the world. It was possible to understand that the educational unit should take advantage of the advantages and potentialities of digital technologies, aiming to favor the development of meaningful learning for 21 st Century students, preparing them to act in the world around them in a healthy and responsible manner.

Keywords: Education. Daily. Digital technologies. Interpersonal Relations.

\section{Introdução}

Cegundo Santos (2016) as tecnologias digitais são meios que podem auxiliar as pessoas nos modos de fazer, inventar e reinventar o mundo. Compreende-se que os processos de aprendizagem são estruturados por instrumentos culturais de um determinado tempo, pelas linguagens e pelos praticantes culturais historicamente situados. Vivemos em um mundo onde é possível desenvolver a aprendizagem de diversas maneiras, pode-se aprender com os colegas em trabalhos em grupo, por meio de mídias e do uso de tecnologias. Nesse contexto, aprender com tecnologias, redes sociotécnicas e currículos que podem ser tanto presenciais como a distância, refere-se a uma realidade concreta e atual.

No contexto educacional, tanto na educação básica como no ensino superior, torna-se necessário a criação de currículos e práticas formativas que contemplem a diversidade coletiva, permitindo que as singularidades possam emergir, potencializando as experiências coletivas dos aprendizes/praticantes culturais. Isso requer uma mudança paradigmática das concepções de educação e o uso de tecnologias e de linguagens que possibilitem uma dinâmica social capaz de romper com certas limitações existentes nos encontros presenciais ou a distância, os quais têm como característica central a transmissão de conteúdos disciplinares (SANTOS, 2016).

A Pesquisa Nacional por Amostra de Domicílios Contínua (PNAD), realizada no quarto trimestre de 2016, contemplou o tema da Tecnologia da Informação e Comunicação (TIC) tendo como um dos tópicos o acesso à internet 
e a posse de telefone móvel para uso pessoal (IBGE, 2016). A investigação abrangeu as pessoas de 10 anos ou mais de idade e focou na sua ocorrência pelo menos em algum momento, no período de referência dos últimos três meses. Os dados mostraram que, na população de cerca de 179.424 mil pessoas de 10 anos ou mais de idade do País, 64,7\% utilizaram a internet no período de referência dos últimos três meses. A utilização da internet mostrou-se crescente com o aumento da idade, alcançando o máximo entre os adultos jovens de 18 a 24 anos de idade e declinando a seguir. No grupo etário de 10 a 13 anos, 66,3\% das pessoas utilizaram a internet e, nos grupos etários de 18 ou 19 anos e 20 a 24 anos de idade, os percentuais ficaram praticamente iguais ( $85,4 \%$ e $85,2 \%$, respectivamente).

Os dados da pesquisa demonstraram que o contingente que utilizou a internet na população estudantil $(81,2 \%)$ foi substancialmente maior que na não estudantil $(60,4 \%)$, e constatou-se diferença marcante $(22,4$ pontos percentuais) entre os indicadores, segundo a rede de ensino frequentada: a parcela dos que acessaram a internet entre os estudantes da rede privada atingiu 97,4\%, enquanto entre os da rede pública ficou em 75,0\%. O telefone móvel celular foi destacadamente o equipamento mais usado para acessar a internet: na população de 10 anos ou mais de idade que utilizou essa rede, $94,6 \%$ (cerca de 109.818 mil pessoas). O segundo equipamento mais empregado foi o microcomputador, por 63,7\% (cerca de 73.973 mil pessoas). Quanto à finalidade do acesso à internet, a que mais se destacou foi a de enviar ou receber mensagens de texto, voz ou imagens por aplicativos diferentes de e-mail, indicada por $94,2 \%$ das pessoas de 10 anos ou mais de idade que utilizaram a internet. Assistir a vídeos, inclusive programas, séries e filmes, foi apontado por $76,4 \%$ dessas pessoas, vindo logo em seguida conversar por chamadas de voz ou vídeo (73,3\%) e, por último, enviar ou receber e-mail (69,3\%) (IBGE, 2016).

No País, $77,1 \%$ da população de 10 anos ou mais de idade tinha telefone móvel celular para uso pessoal. No contingente de cerca de 138.320 mil pessoas de 10 anos ou mais de idade que tinham telefone móvel celular para uso pessoal, 78,9\% tinham acesso à Internet por meio desse aparelho. O percentual de pessoas que tinham telefone móvel celular para uso pessoal por grupos etários que teve o seu mínimo na faixa de 10 a 13 anos (39,8\%), subiu abruptamente na faixa etária de 14 a 17 anos $(70,0 \%)$ e prosseguiu em crescimento, alcançando maior representatividade entre os adultos jovens de 25 a 34 anos $(88,6 \%)$ e de 35 a 39 anos (88,2\%), passando, gradualmente, a declinar nos grupos seguintes, até atingir $60,9 \%$ entre os idosos de 60 anos ou mais de idade (IBGE, 2016)

Os dados recentes divulgados pelo IBGE (2016) mostram que o telefone móvel com acesso à internet é utilizado por grande parte da população jovem - com idade para frequentar o ensino básico e/ou o ensino superior - com o objetivo de trocar mensagens, assistir vídeos e séries, assim como fazer pesquisas. Os dados mostram o quanto as tecnologias digitais estão no dia a dia da população jovem, afetando, consequentemente, o cotidiano educacional.

Desse modo, compreende-se que o acesso, o uso criativo e consciente das diversas tecnologias digitais podem contribuir para o desenvolvimento de relações interpessoais, por meio da realização de diversas atividades no decorrer 
do processo de ensino e aprendizagem, visando qualificar a formação dos estudantes do século XXI. Em vista disso, indaga-se "Como as tecnologias digitais impactam as relações interpessoais no cotidiano das instituições educativas"? A temática escolhida está relacionada com as propostas das teses de doutorado das autoras, sendo que as relações interpessoais na educação básica serão trabalhadas pela primeira autora e as tecnologias digitais no ensino superior serão trabalhadas pela segunda autora em tese doutoral.

Trata-se de um olhar sobre o cotidiano acadêmico do jovem e suas relações interpessoais mediadas pelo uso das tecnologias digitais pela lente de autores de teses e dissertações. O cotidiano é um espaço de complexidade e é visto, portanto,

como um rico espaço de construção de conhecimentos, os professores como sujeitos de conhecimentos, assim como as crianças como sujeitos de saberes e a escola como locus de diferentes saberes que dialogam dialeticamente possibilitando ser cumprida a promessa de uma escola que contribua efetivamente para mudar as vidas de quem nela chega e por ela passa grande parte de sua vida (GARCIA, 2003, p. 204).

Para tanto, o artigo tem por objetivo analisar as possibilidades de utilização das tecnologias digitais e seus impactos nas relações interpessoais no cotidiano das instituições educativas através de pesquisas produzidas no Brasil entre os anos de 2015 e 2019.

\section{Metodologia}

A metodologia utilizada neste trabalho é de caráter qualitativo exploratório, pautado nos princípios de estado de conhecimento e tem como fonte principal a Biblioteca Digital Brasileira de Teses e Dissertações (BDTD). O corpus de análise constituiu-se por doze (12) dissertações de mestrado e seis (6) teses de doutorado.

De acordo com Morosini (2015) o estado de conhecimento relaciona-se ao processo de identificação, registro e categorização, tendo por finalidade o desenvolvimento da reflexão e da síntese acerca da produção científica de uma área específica, em um determinado período de tempo, podendo englobar teses, dissertações, periódicos e livros referentes a uma determinada temática. O presente trabalho limitou-se ao escopo das teses e dissertações desenvolvidas em programas de pós-graduação nacionais.

Tendo a intenção de analisar a produção científica a partir da definição do tema, com a clarificação do questionamento de partida, foram selecionados alguns descritores (palavras-chave) articulados a essa temática, objetivando buscar e encontrar os trabalhos necessários para a elaboração do estudo. Vale ressaltar que o banco 
de dados selecionado como fonte de pesquisa diz respeito à Biblioteca Digital de Teses e Dissertações (BDTD) do Instituto Brasileiro de Informação em Ciência e Tecnologia (IBICT).

Primeiramente foram utilizadas as palavras-chave "tecnologias digitais; relações interpessoais", o recurso da busca foi a avançada, ordenada por relevância, no período entre 2015 e 2019, visando assim encontrar as pesquisas mais recentes nesse campo temático. Desse modo, foram encontrados quinze (15) trabalhos, sendo selecionados dez (10) no banco de dados mencionado. Cinco (5) estudos foram descartados por não estarem relacionados ao objeto de estudo.

$\mathrm{Na}$ segunda busca, foram utilizadas as palavras-chave "tecnologias digitais; convivência" e foram utilizados os mesmos recursos abordados anteriormente, a fim de ampliar os dados coletados. Desse modo, foram encontrados dezesseis (16) trabalhos, porém foram selecionados onze (11) no banco de dados referido. Cinco (5) estudos não foram aproveitados por não contemplarem a temática proposta neste trabalho, referindo-se ao mundo dos negócios e a questões empresariais. Além disso, três (3) estudos se repetiram nesta segunda análise em relação à primeira busca realizada.

Sendo assim, a partir das duas buscas realizadas foram selecionados ao todo dezoito (18) teses e dissertações, o que inclui doze (12) dissertações de mestrado e seis (6) teses de doutorado, estando todos relacionados à temática pesquisada, constituindo o corpus de análise. No Quadro 1 são apresentadas as etapas de busca e seleção de estudos científicos (teses e dissertações) a serem analisados, tendo o propósito de responder o problema de pesquisa proposto:

Quadro 1 - Etapas de busca e seleção de estudos científicos no banco de dados da BDTD do IBCT

\begin{tabular}{|l|c|c|c|}
\hline Descritor & Tipo de busca & $\begin{array}{c}\text { No de teses e dissertações } \\
\text { encontradas }\end{array}$ & $\begin{array}{c}\text { No de teses e dissertações } \\
\text { selecionadas }\end{array}$ \\
\cline { 1 - 3 } Tecnologias digitais; Relações interpessoais & \multirow{2}{*}{$\begin{array}{c}\text { Avançada; ordenada por } \\
\text { relevância; 2015-2019 }\end{array}$} & 15 & 10 \\
\cline { 1 - 4 } Tecnologias digitais; Convivência & 2 buscas & 16 & 8 \\
\cline { 1 - 4 } Total & 31 & 18 \\
\hline
\end{tabular}

Fonte: Elaborado pelas autoras (2019).

Posteriormente à seleção do corpus de análise foi realizada uma leitura flutuante dos estudos para a identificação e organização das bibliografias, tal como, a anotada, a sistematizada e a categorizada, conforme mencionadas por Morosini e Nascimento (2017). A leitura flutuante permitiu a elaboração da primeira etapa de organização dos dados, correspondente à bibliografia anotada. Nesse momento, os estudos científicos selecionados foram organizados em uma tabela com a referência bibliográfica completa e o seu respectivo resumo.

Logo após, foi realizada a segunda etapa da organização dos dados coletados, dessa forma foi preciso realizar novamente a leitura das produções científicas selecionadas, para organizar os dados em uma segunda tabela, a qual 
foi denominada como bibliografia sistematizada. Para tanto, foi apresentado cada trabalho selecionado, constando ano de defesa, instituição e programa de pós-graduação, autor, título, nível da pós-graduação, objetivo, metodologia e resultados. Nessa etapa, foi necessária a busca por informações contidas em outras partes do trabalho, perpassando o resumo do mesmo.

Para finalizar a etapa referente à organização dos dados, foi elaborada a tabela sobre a bibliografia categorizada, para isso foi preciso realizar um reagrupamento da bibliografia sistematizada segundo o critério temas abordados. Sendo assim, as três categorias resultantes dessa etapa serão apresentadas a seguir.

\section{Resultados}

O corpus de análise constituiu-se por doze (12) dissertações de mestrado e seis (6) teses de doutorado sobre a temática das tecnologias digitais e das relações interpessoais/convivência. Em 2015, foram identificadas quatro (4) dissertações e uma (1) tese de doutorado; em 2016, foram identificadas apenas uma (1) dissertação e uma (1) tese; em 2017 foram encontrados duas (2) dissertações e duas (2) teses; 2018 quatro (4) dissertações e uma (1) tese; e em 2019 uma (1) dissertação e uma (1) tese (Gráfico 1).

Gráfico 1 -Teses e dissertações distribuídas por ano de publicação

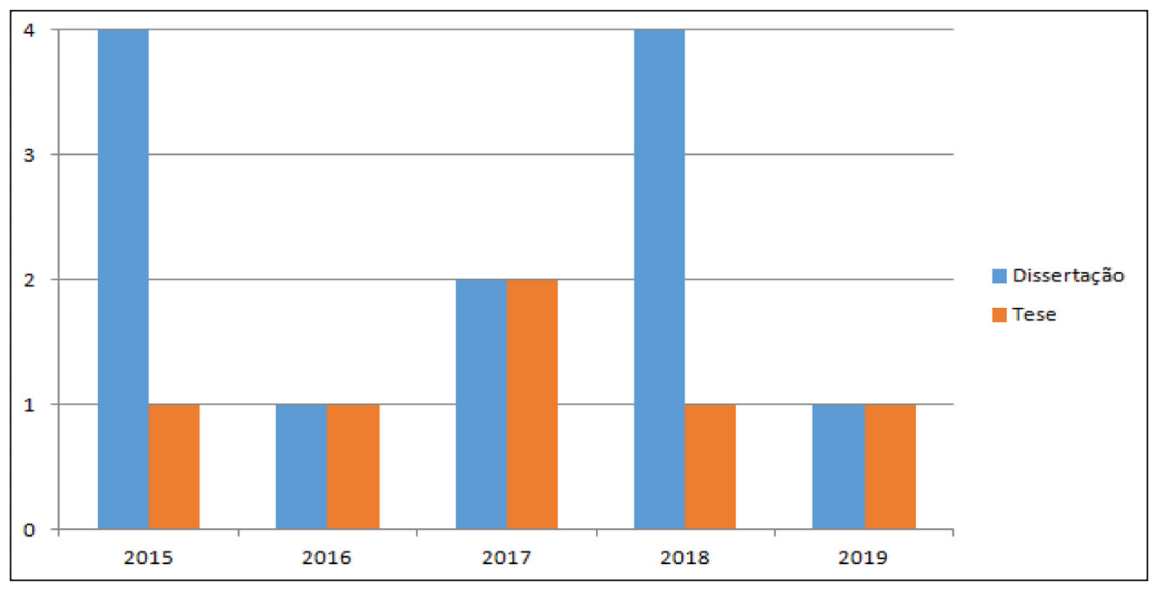

Fonte: Elaborado pelas autoras (2019). 
A maioria das dissertações e teses foi produzida em programas de pós-graduação da região Sudeste (7), seguida pela região Sul (6), região Nordeste (3) e Centro-Oeste (2). Chama atenção o fato de não serem encontradas nenhuma produção da região Norte como mostra o Gráfico 2.

Gráfico 2 - Dissertações e teses distribuídas por região

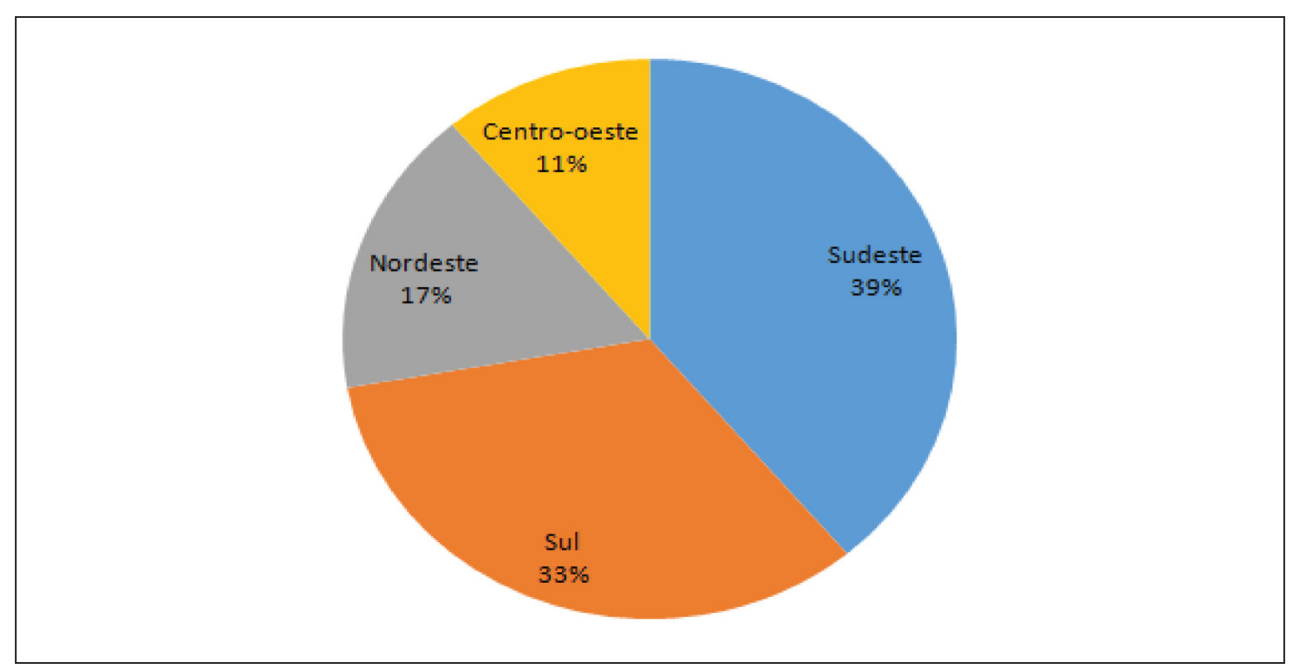

Fonte: Elaborado pelas autoras (2019).

As produções científicas foram organizadas em três categorias, a saber: (1) uso das tecnologias digitais na aprendizagem dos estudantes; (2) impacto das tecnologias digitais no cotidiano dos estudantes; e (3) formação de professores no cotidiano das instituições educativas.

\section{Categoria 1: uso das tecnologias digitais na aprendizagem dos estudantes}

A primeira categoria "uso das tecnologias digitais na aprendizagem dos estudantes" contempla sete trabalhos, conforme exposto na Tabela 1. 
Tabela 1 - Teses e dissertações da categoria 1

\begin{tabular}{|c|c|c|c|}
\hline Autor & Título & Ano & Produção Científica \\
\hline $\begin{array}{l}\text { CARVALHO, Paulo Jorge de } \\
\text { Oliveira. }\end{array}$ & $\begin{array}{l}\text { Discurso pedagógico na educação permanente em saúde: estudo de curso } \\
\text { de Educação a Distância no Ensino Superior }\end{array}$ & 2018 & Tese \\
\hline LIMA, Anne Caroline Araújo de. & Multiletramentos na formação do(a) professor(a) de Língua Portuguesa & 2018 & Dissertação \\
\hline MACHADO, Márcia Buffon. & (Trans)formação de professores em acoplamento com as tecnologias digitais & 2015 & Dissertação \\
\hline OLIVEIRA, Inês Naves Cunha de & $\begin{array}{l}\text { A construção de bandeiras: um cenário para exploração da geometria via } \\
\text { tecnologia e interdisciplinaridade no Ensino Fundamental }\end{array}$ & 2019 & Dissertação \\
\hline OLIVEIRA, Marcos Lopes de. & $\begin{array}{l}\text { Generalização de padrões e tecnologias digitais: estratégias didáticas para a } \\
\text { aprendizagem }\end{array}$ & 2018 & Dissertação \\
\hline PEREIRA, Ednaldo Coelho. & $\begin{array}{l}\text { Interação e relações interpessoais na ambiência de um sistema de educação } \\
\text { presencial mediado por recursos tecnológicos }\end{array}$ & 2017 & Tese \\
\hline SILVA, Sandra Regina & $\begin{array}{l}\text { O ensino de língua estrangeira nas escolas públicas estaduais paulistas e as } \\
\text { novas tecnologias }\end{array}$ & 2016 & Dissertação \\
\hline
\end{tabular}

Fonte: Elaborado pelas autoras (2019).

Diante da constatação da influência crescente das mídias digitais no espaço escolar, Silva (2016) realizou observações nos cursos presenciais e online de Língua Estrangeira, disponibilizados para estudantes do ensino fundamental e médio das escolas estaduais paulista. A autora observou o uso frequente de vídeos e áudios por parte dos professores participantes do estudo em suas aulas. Ao abordar a relação existente entre ensino da Língua Estrangeira e as Tecnologias de Informação e Comunicação (TIC) a autora constatou que as TICs são recursos pedagógicos versáteis utilizados tanto para erradicar o analfabetismo como para contribuir com a formação e a atualização de educadores. Em sua visão, possui grande potencial inclusivo e contribui com a aproximação das diferentes culturas. Nas considerações finais Silva (2016, p. 87) reflete:

A resistência dos estudantes que ocuparam escolas na capital e em várias cidades do interior do estado de São Paulo contra a desastrosa reorganização escolar da Secretaria de Educação do Estado de São Paulo em 2015 e que impactaria 1,4 milhão dos 4 milhões de estudantes da rede, com o fechamento de 92 escolas e o funcionamento de um único ciclo escolar em cada unidade conduziu a pesquisadora ao questionamento sobre como investigar sobre as novas tecnologias no ensino de língua estrangeira num momento de aguda crise do ensino público estadual paulista. Como falar sobre a tecnologia nas aulas de inglês e espanhol quando muitos estudantes do ensino fundamental e médio de todo o estado de São Paulo lutavam pelo direito básico de manter a escola aberta e resistiam contra a mudança compulsória para outras unidades escolares indo para as ruas em protestos? 
A citação acima provoca uma reflexão sobre o inesperado, não previsto, que surge nas pesquisas que envolvem o cotidiano. Nas rotas do cotidiano (PAIS, 1993) ocorre um movimento oscilante de descobrimento e encobrimento onde tudo parece provisório. O cotidiano "não é uma parcela isolável do social" (PAIS, 1993, p. 111), suas rotas são caminhos que revelam múltiplos enredos da vida social que escapam aos caminhos previamente estipulados pelo pesquisador.

Lima (2018) procurou investigar o nível de letramento digital de docentes de Língua Portuguesa (em formação continuada) e de licenciandos(as) em Letras-Português. Para tanto, pesquisou quatro docentes atuantes em instituições de ensino básico que dispõem de recursos tecnológicos para uso dos professores e que utilizaram, em algum momento ao longo do ano, tecnologias digitais em suas aulas de Língua Portuguesa. Foram citadas ferramentas como aplicativos, sites e/ou softwares educacionais como áudios, imagens e/ou vídeos, Word e/ou Power Point. Os dados, segundo a autora, contrastaram um pouco com a diversidade de tecnologias utilizadas diariamente pelas mesmas professoras para fins pessoais, já que no seu dia a dia utilizavam mais ferramentas e recursos digitais do que colocavam em prática no planejamento pedagógico. A autora descreve que as professoras participantes do seu estudo afirmaram que seria importante promover um elo entre ensino, aprendizagem e tecnologias digitais, e destacaram a necessidade de subsídios teórico-metodológicos no decorrer de suas formações para interligar os saberes.

Pensando na utilização das ferramentas digitais para a promoção da aprendizagem dos estudantes, Oliveira (2019) acompanhou um projeto realizado no estudo de geometria com noventa estudantes de sexto ano de uma escola municipal na cidade de Uberlândia/MG, a partir do desenvolvimento de uma proposta interdisciplinar, na qual professores de três outras áreas do conhecimento contribuíram no desenvolvimento dessa. Objetivou-se investigar em quais aspectos a prática interdisciplinar aliada ao uso do software GeoGebra pôde influenciar no interesse e na aprendizagem de conceitos geométricos por parte dos estudantes. O pesquisador observou mudanças no comportamento dos jovens e em sua receptividade em relação ao conteúdo aplicado, além disso, o desenvolvimento de atividades no laboratório de informática tornou-se uma motivação para as aulas contribuindo com a aprendizagem dos estudantes.

Em outro estudo envolvendo o ensino de álgebra na educação básica, Oliveira (2018) procurou entender como a tecnologia pode potencializar o aprendizado do aluno empregando problemas e/ou situações que envolvam a generalização de padrões como tema central. Neste sentido, procurou-se estabelecer um diálogo entre a pedagogia e a tecnologia, propondo uma convivência equilibrada entre elas.

No que se refere ao ensino superior a distância, Carvalho (2018) investigou o uso de tecnologias digitais na estruturação do discurso pedagógico nessa modalidade de ensino, na educação a distância do ensino superior com foco na Educação Permanente em Saúde por meio da análise do ambiente virtual de aprendizagem do curso, hospedado na Plataforma para Comunidades de Prática OTICS. A coleta de dados ocorreu em documentos que compõem a 
estrutura do curso sobre aspectos administrativos e normativos, além do material didático e das práticas de ensino e aprendizagem registradas nos fóruns de interação.

A necessidade de se estudar mais sobre a educação a distância também levou Pereira (2017) a aprofundar seus estudos sobre um modelo de educação denominado de Sistema Presencial Mediado por Recursos Tecnológicos, que faz uso das Tecnologias Digitais de Informação e Comunicação (TDIC) para transmissão de suas aulas em tempo real. Trata-se de um modelo híbrido que reúne as características dos cursos presenciais e da Educação a Distância (EaD) ao mesmo tempo, pois requer a presença de alunos em sala de aula no mesmo horário da transmissão. No que diz respeito às relações interpessoais, o sistema analisado atende parcialmente às necessidades dos sujeitos (professores e estudantes) nos quesitos comunicação e interação, prejudicando, de acordo com o autor, o estabelecimento e a manutenção das várias relações possíveis e, por consequência, influenciam nas atividades acadêmicas do curso investigado.

Com o objetivo de traçar um panorama das práticas discentes, Machado (2015) avaliou as produções, de 2009 e 2014, observadas na disciplina de Trabalho Final de Graduação do curso de Arquitetura da Universidade de Fortaleza nos momentos de concepção e de apresentação dos projetos. O material avaliado revelou grande atenção dispensada a desenhos específicos durante o processo do projeto, destacando-se as plantas e as perspectivas. Constatou-se o uso frequente do desenho à mão livre e que os instrumentos digitais, vistos como auxiliares dos desenhos analógicos, por vezes não eram abordados nas disciplinas de desenho. O autor chama atenção para a necessidade dos currículos acadêmicos definirem e assumirem um desenho específico para o arquiteto, levando em consideração as possibilidades tecnológicas, analógicas e digitais.

\section{Categoria 2: impacto das tecnologias digitais no cotidiano dos estudantes}

A segunda categoria "impacto das tecnologias digitais no cotidiano dos estudantes" contempla cinco trabalhos conforme exposto na Tabela 2.

Tabela 2 - Teses e dissertações da categoria 2

\begin{tabular}{|c|c|c|c|}
\hline Autor & Título & Ano & $\begin{array}{l}\text { Produção } \\
\text { Científica }\end{array}$ \\
\hline BORTOLAZZO, Sandro Faccin & Narrativas acadêmicas e midiáticas produzindo uma geração digital & 2015 & Tese \\
\hline FERNANDES, Larissa Krüger & Infância Urbana e novas tecnologias: uma análise pela perspectiva da criança & 2018 & Dissertação \\
\hline MUSSIO, Rogéria Albertinase Pincelli & A Geração Z e suas respostas comportamental e emotiva nas redes sociais virtuais & 2017 & Dissertação \\
\hline NEJM, Rodrigo & Exposição de si e gerenciamento da privacidade de adolescentes nos contextos digitais & 2016 & Tese \\
\hline TONATTO, Regiane Cristina & Este barco é nosso!: do ciberespaço aos caminhos rumo à alteridade & 2017 & Dissertação \\
\hline
\end{tabular}

Fonte: Elaborado pelas autoras (2019). 
O adolescente contemporâneo vive em um mundo digital cujas relações são perpassadas pela tecnologia. O jovem está constantemente conectado, o que pode impactar nas suas relações "reais". Diante desse panorama, Mussio (2017) realizou um estudo transversal com o objetivo de analisar como os adolescentes utilizam as novas mídias digitais e as redes sociais em seus relacionamentos interpessoais e na comunicação virtual. Participaram desse estudo 267 adolescentes estudantes de escola pública com idades entre 14 e 17 anos com acesso à internet e às redes sociais. A partir da aplicação de um questionário, foi possível identificar que, embora não seja frequente, o uso das redes sociais pode provocar respostas emocionais intensas nos adolescentes, existindo diferenças entre os comportamentos de meninos e meninas na interação virtual. As relações dos adolescentes nas redes sociais virtuais com os amigos e as pessoas próximas são intensas. Apesar de não terem sido encontrados fortes indícios de dependência tecnológica na amostra analisada e nem dificuldades de comunicação, verificou-se que os adolescentes buscam conectar-se online rapidamente e manifestam certa ansiedade e irritabilidade quando não conseguem conectar-se à internet.

De acordo com Fernandes (2018), as novas tecnologias da informação e comunicação têm se feito cada vez mais presentes no diaadia das crianças desde muito cedo, intermediando várias de suas ações. Tablets e celulares aparecem entre os objetos tecnológicos manipulados quase que diariamente, principalmente em espaços urbanos. Diante dessa nova realidade, a autora procurou entender como as crianças têm percebido a presença desses objetos em suas vidas através de suas narrativas. Constatou-se que as crianças participantes da pesquisa - quatro ao todo com idades entre 9 e 12 anos - percebem as novas tecnologias como integradas em suas rotinas, participantes de seus processos de comunicação, de construção de conhecimento, de acesso a entretenimento e de ação no cotidiano. As crianças reconhecem a possibilidade de se encontrarem com outras pessoas no espaço online, sendo uma alternativa ao mundo real.

Para Nejm (2016), as relações afetivas dos adolescentes, as relações de trabalho, os estudos e o lazer passam a ter dispositivos tecnológicos como mediadores. O autor realizou uma análise qualitativa sobre a exposição dos adolescentes nos contextos digitais, atentando para as estratégias utilizadas para gerenciar suas privacidades. Através de entrevistas individuais sobre as exposições nos aplicativos e redes sociais como Facebook, Instagram, WhatsApp e Snapchat, e de observações das publicações nos perfis do Facebook e Instagram, o autor verificou que compartilhar informações privadas nos contextos digitais não significa o abandono da preocupação com a privacidade, mas sim novos limites, com regras definidas individual e coletivamente, negociadas para cada plataforma e para cada grupo de alvos das exposições. Apesar do uso diário, intenso e privativo pelos celulares, com uma grande quantidade de amigos no Facebook, seguidores no Instagram e contatos no WhatsApp e Snapchat, os relacionamentos interpessoais e as exposições dos adolescentes participantes do estudo ocorrem prioritariamente com as mesmas pessoas que conhecem de encontros presenciais.

De acordo com Tonatto (2017), vivemos em um contexto marcado pelas relações em redes digitais cujas conexões podem transformar as pessoas impactando nas instituições e na sociedade como um todo. A escola apresenta-se como 
um espaço onde essas transformações são profícuas. A pesquisadora reuniu depoimentos de pessoas com e sem deficiência, incluídas na escola pública respondendo à questão: como a alteridade está presente em um ciberespaço inclusivo e consciente, e o que pensam jovens e adultos estudantes com e sem deficiência sobre as mídias em relação à acessibilidade. A revisão bibliográfica possibilitou à autora pensar as tecnologias e suas mídias, não como uma mera aquisição de materiais, mas, como possibilidades de contribuir para ampliar os espaços e tempos da universalidade, bem como acesso e convívio nos espaços privilegiados de encontros.

Bortolazzo (2015) procurou mapear as narrativas acadêmicas que demarcam uma geração conectada às tecnologias digitais - a geração digital. O mapeamento das narrativas midiáticas acerca dessa geração foi realizado mediante uma análise das reportagens de capa de duas revistas semanais - Veja e Época - no período de 15 anos (entre 1998 e 2013). Os resultados da pesquisa evidenciam uma geração que vem sendo instituída por narrativas que apontam a convivência, a familiaridade e a habilidade para operar ferramentas digitais como o que distingue os jovens digitais de outras gerações. $\mathrm{O}$ autor observou que, ao associar determinadas características a crianças e jovens, tais como a facilidade em utilizar smartphones e tablets, as narrativas acadêmicas e midiáticas acabam produzindo verdades sobre a sociedade e os sujeitos que nela vivem.

\section{Categoria 3: formação de professores no cotidiano das instituições educativas}

A terceira e última categoria "formação de professores no cotidiano das instituições educativas" contempla seis trabalhos conforme exposto na Tabela 3.

Tabela 3 - Teses e dissertações da categoria 3

\begin{tabular}{|c|c|c|c|}
\hline Autor & Título & Ano & $\begin{array}{l}\text { Produção } \\
\text { científica }\end{array}$ \\
\hline AMARAL, Caroline Bohrer do & Estratégias pedagógicas para o ensino fundamental: um enfoque na dimensão socioafetiva & 2017 & Tese \\
\hline BERSCH, Maria Elisabete & $\begin{array}{l}\text { Formação continuada de professores: gamificação em espaços de convivência e } \\
\text { aprendizagem híbridos e multimodais }\end{array}$ & 2019 & Tese \\
\hline BIANCHI, Cintia Santos Tolosa & Uso pedagógico do celular e o papel do supervisor da Rede Estadual de Ensino de São Paulo & 2015 & Dissertação \\
\hline FERREIRA, Dirlene Almeida & $\begin{array}{l}\text { Elaboração, implementação e avaliação de um curso de formação continuada em Educação } \\
\text { em Valores na modalidade EaD }\end{array}$ & 2018 & Dissertação \\
\hline MACHADO, Márcia Buffon & (Trans)formação de professores em acoplamento com as tecnologias digitais & 2015 & Dissertação \\
\hline STIEH, Daniela da Graça & $\begin{array}{l}\text { Do pré-digital ao digital: o percurso das interações de professores em escola participante de } \\
\text { programa de Inclusão Digital }\end{array}$ & 2015 & Dissertação \\
\hline
\end{tabular}

Fonte: Elaborado pelas autoras (2019). 
O estudo de Ferreira (2018) teve como objetivo analisar um curso de formação continuada a distância sobre a temática Educação em Valores destinado a professores de Educação Física dos Anos Finais do Ensino Fundamental de uma escola de Fortaleza. Os resultados indicaram que não há um consenso por parte dos pesquisados quanto à inclusão da $\mathrm{EaD}$ na formação continuada de professores. Parte dos entrevistados concorda com o modelo de ensino, defendendo a forma semipresencial e outra parte prefere os encontros formativos presenciais. Os participantes demonstraram conhecimento mínimo tecnológico para participar do curso EaD e razoável proximidade com as ferramentas digitais. O ensino a distância exige mais disciplina e motivação do aluno para sua continuidade e finalização, apesar de ter como pontos positivos a adequação de tempo, espaço e ritmo de vida. Quanto ao uso das tecnologias, as principais dificuldades foram: na inserção de arquivo na base de dados e a utilização do fórum. Os docentes indicaram que o curso contribuiu para o trato da temática valores em aulas de Educação Física.

Amaral (2017) procurou investigar como estratégias pedagógicas contribuem para o desenvolvimento da dimensão socioafetiva de estudantes do ensino fundamental. Os participantes da pesquisa constituíram-se por professores do ensino fundamental das redes pública e privada que participaram voluntariamente de duas edições de um curso de extensão sobre a dimensão socioafetiva e sobre as tecnologias digitais na Educação. Os dados foram coletados em entrevistas e registros de atividades realizadas durante o curso. Os resultados mostraram que as estratégias pedagógicas adotadas pelos professores contribuem em alguns momentos para a autonomia e em outros para a heteronomia na relação entre professor e estudantes. As antecipações acerca das intervenções nas relações interpessoais e na gestão de conflitos estiveram ausentes dos planejamentos para ambientes virtuais. A autora considera que, para haver transformações no âmbito da convivência social em ambientes presenciais e virtuais, é necessário avanços no desenvolvimento da dimensão socioafetiva de professores e de estudantes. Diante disso, é necessário que a formação docente, inicial e continuada, atue intencionalmente nesse sentido.

Machado (2015) buscou compreender as transformações que aconteceram com professores que participaram de um grupo de estudos acerca da reestruturação do ensino médio, no contexto de inserção das tecnologias digitais na escola, proposto como espaço de convivência entre professores em formação continuada com foco na tecnologia. Foram feitos registros em diários a partir de entrevistas cartográficas realizadas com cinco professoras que aceitaram participar do grupo de estudo - "Ensino Médio: realidades, tecnologia, possibilidades e (re)construções". A autora considera que repensar e reorganizar os espaços, tempos e currículos escolares parece ser importante para a acolhida de alunos e professores, a fim de que sejam possíveis ações respeitosas, colaborativas e cooperativas entre professores, alunos e comunidade escolar na busca pela educação integral e contemporânea, na qual os sujeitos se transformem e sejam capazes de pensar e agir por uma vida responsável e autônoma. 
Stieh (2015) investigou o percurso das interações de professores no contexto de uma Escola Estadual de Ensino Fundamental, localizada no município de Sapucaia do Sul/RS, a qual tem participado de programas de inclusão digital. Os sujeitos da pesquisa foram professores que atuam na escola desde o momento em que as tecnologias digitais passaram a fazer parte do cotidiano da escola a partir do programa de inclusão digital na modalidade de um computador por aluno. O dinamismo das interações nesse contexto e os seus percursos foram investigados a partir da passagem e da convivência entre mídias analógicas e digitais, identificadas nessa pesquisa como: pré-digital e digital. De acordo com a autora, a pesquisa possibilitou a transformação da realidade dos professores com relação às interações a partir das reflexões e da atenção aos espaços da escola, tanto no digital quanto no pré-digital.

Diante da dificuldade de professores e das equipes escolares administrarem a intensa relação entre alunos e seus telefones celulares, Bianchi (2015) destaca o papel do supervisor de ensino nessa dinâmica. Para tanto, procurou compreender como seria possível oferecer subsídios ao supervisor de ensino da rede estadual de São Paulo para que ele reconheça o celular como ferramenta pedagógica. A investigação teve por objetivo principal elaborar uma proposta de formação continuada em $\mathrm{EaD}$, dirigida aos supervisores de ensino, no sentido de ajudá-los a reconhecer o celular como recurso auxiliar à prática educacional, considerando as suas possibilidades de uso pedagógico.

Bersch (2019) procurou investigar como a configuração de Espaços de Convivências e Aprendizagem Híbridos e Multimodais pode contribuir para a formação continuada de professores, aproximando universidade e escolas, tendo em vista a promoção de novos saberes docentes e práticas pedagógicas gamificadas. A pesquisa caracterizouse pelo desenvolvimento de um processo de formação continuada, na perspectiva da configuração de Espaços de Convivência e Aprendizagem Híbridos e Multimodais, da qual participaram 81 professores da rede pública de três municípios do Rio Grande do Sul, durante o período de 20 meses, totalizando cerca de 166 horas de formação. Os resultados indicaram que a formação docente, na perspectiva da configuração de Espaços de Convivência e Aprendizagem Híbridos e Multimodais, possibilita ampliar os espaços formativos e a aproximação dos diferentes atores, proporcionando mudanças nas práticas pedagógicas desenvolvidas nas escolas.

\section{Considerações finais}

Com o objetivo de buscar respostas à questão: "como as tecnologias digitais impactam as relações interpessoais no cotidiano das instituições educativas?" foi proposta uma análise de teses e dissertações desenvolvidas em programas de pós-graduação nacionais nos últimos cinco anos sobre a temática.

As produções científicas apontaram que há uma crescente influência das tecnologias digitais nos espaços educacionais, podendo ser recursos pedagógicos versáteis e importantes no planejamento dos professores. O uso das 
ferramentas digitais pode proporcionar mais interesse por parte dos estudantes aos conteúdos escolares, impactando na sua motivação e no seu interesse (OLIVEIRA, 2019), potencializando, consequentemente, sua aprendizagem (OLIVEIRA, 2018).

A análise das teses e dissertações possibilitou confirmar a percepção de que os jovens atualmente vivem em um mundo cujas relações são perpassadas pelas tecnologias digitais, estando constantemente conectados. Podem promover intensas relações nas redes virtuais (MUSSIO, 2017), devendo ter uma atenção especial às estratégias para gerenciar suas privacidades online (NEJIM, 2016). Também possibilitou constatar que dispositivos- como tablets e celulares, por exemplo, têm estado presentes desde muito cedo no cotidiano das crianças pequenas (FERNANDES, 2018), impactando na sua forma de ver o mundo - real e virtual.

A tecnologia também foi apontada na literatura analisada como possibilidade de os jovens estarem conectados com outras culturas (SILVA, 2016), assim como uma possibilidade de incluir crianças e jovens com necessidades educativas especiais (NEEs) - nas instituições de ensino, seja da educação básica ou do ensino superior (TONATTO, 2017).

A grande maioria das produções científicas apontou a necessidade da formação continuada dos professores. Não basta as instituições de ensino disponibilizarem recursos tecnológicos sem proporcionar orientação adequada. Além disso, foi apontada a necessidade de formação tanto no que diz respeito ao letramento digital (LIMA, 2018), promovendo, consequentemente, mudanças nas práticas pedagógicas (BERSCH, 2019), quanto a aspectos relacionados à dimensão socioemocional (AMARAL, 2017; FERREIRA, 2018).

A partir desse estudo foi possível compreender que cabe a unidade educativa ser um ambiente favorável de formação humana integral, proporcionando atividades que possibilitem a reflexão, o debate e a vivência de valores para a construção de relações interpessoais harmoniosas, sadias e duradouras e, também de convivência democrática e respeitosa entre os envolvidos no processo educativo, questões essas consideradas indispensáveis em diversos momentos da vida cotidiana.

Para tanto, a instituição de educação pode aproveitar as vantagens e as potencialidades das tecnologias digitais, visando favorecer o desenvolvimento de aprendizagens significativas aos estudantes do século XXI, preparando-os assim para atuarem no mundo que os rodeia de maneira saudável e responsável.

A partir do questionamento de Regina Leite Garcia (GARCIA, 2001, p. 18): "nossas pesquisas, reflexões e escritos contribuem para estabelecer um fértil diálogo universidade-escola ou apenas ampliam o fosso entre estes dois níveis de escolaridade", espera-se que o presente estudo chegue até as escolas e instituições de ensino superior, beneficiando toda a comunidade escolar, ampliando o conhecimento e melhorando o trabalho pedagógico. 


\section{Referências}

AMARAL, Caroline Bohrer do. Estratégias pedagógicas para o Ensino Fundamental: um enfoque na dimensão socioafetiva. 2017. 253 f. Tese (Doutorado em Educação) - Programa de Pós-Graduação em Educação, Universidade Federal do Rio Grande do Sul, Porto Alegre, 2017. https://doi.org/10.24243/jmeb/3.5.207

BERSCH, Maria Elisabete. Formação continuada de professores: gamificação em de convivência e aprendizagem híbridos e multimodais. 2019. 268 f. Tese (Doutorado em Educação) - Programa de Pós-Graduação em Educação, Universidade do Vale dos Sinos, São Leopoldo, 2019. https://doi.org/10.21041/conpat2019/v2pat80

BIANCHI, Cintia Santos Tolosa. Uso pedagógico do celular e o papel do supervisor da Rede Estadual de Ensino de São Paulo. 2015. 98 f. Dissertação (Mestrado em Educação) - Pontifícia Universidade Católica de São Paulo, São Paulo, 2015. https://doi. org/10.5327/z1984-4840201623647

BORTOLAZZO, Sandro Faccin. Narrativas acadêmicas e midiáticas produzindo uma geração digital. 2015. 206f. Tese (Doutorado em Educação) - Faculdade de Educação, Universidade Federal do Rio Grande do Sul, Porto Alegre, 2015. https://doi. org/10.29289/259453942018v28s1059

CARVALHO, Paulo Jorge de Oliveira. Discurso pedagógico na educação permanente em saúde: estudo de curso de educação a distância no Ensino Superior. 2018. 348 f. Tese (Doutorado em Educação: História, Política, Sociedade) - Programa de Estudos PósGraduados em Educação: História, Política, Sociedade, Pontifícia Universidade Católica de São Paulo, São Paulo, 2018. https://doi. org/10.11606/issn.2238-6149.v18i3pi-ii

FERNANDES, Larissa Krüger. Infância urbana e novas tecnologias: uma análise pela perspectiva da criança. 2018 . $142 \mathrm{f}$. Dissertação (Mestrado em Processos de Desenvolvimento Humano e Saúde) - Programa de Pós-Graduação em Processos de Desenvolvimento Humano e Saúde, Universidade de Brasília, Brasília, DF, 2018. https://doi.org/10.21115/jbes.v8.n1.p39-46

FERREIRA, Dirlene Almeida. Elaboração, implementação e avaliação de um curso de formação continuada em Educação em Valores na modalidade EaD. 2018. 138 f. Dissertação (Mestrado em Desenvolvimento Humano e Tecnologias) - Instituto de Biociências de Rio Claro, Universidade Estadual Paulista, Rio Claro, 2018. https://doi.org/10.26512/2016.03.t.20986

GARCIA, R. L. Para quem investigamos - para quem escrevemos: reflexões sobre a responsabilidade social do pesquisador. In: GARCIA, R. L. (org). Para quem pesquisamos para quem escrevemos: o impasse dos intelectuais. São Paulo: Cortez, 2001, p. 15-41. https://doi.org/10.12957/polemica.2018.39420

GARCIA, R. L. A difícil arte/ciência de pesquisar com o cotidiano. In: GARCIA, R. L. (org). Método, Métodos, Contramétodos. São Paulo: Cortéz, 2003. p. 193-209. 
INSTITUTO BRASILEIRO DE GEOGRAFIA E ESTATÍSTICA (IBGE). Pesquisa nacional por amostra de domicílios contínua.

Rio de Janeiro: IBGE, 2016. Disponível em: https://www.ibge.gov.br/estatisticas/multidominio/condicoes-de-vida-desigualdade-e-

pobreza/17270-pnad-continua.html?edicao=19937\&t=sobre. Acesso em: 01 nov. 2019. https://doi.org/10.21710/rch.v25i0.451

LIMA, Anne Caroline Araújo de. Multiletramentos na formação do(a) professor(a) de Língua Portuguesa. $2018.217 \mathrm{f}$.

Dissertação (Mestrado em Letras) - Programa de Pós-Graduação em Letras, Universidade Federal de Pernambuco, Centro de Artes e

Comunicação, Recife, 2018. https://doi.org/10.12957/matraga.2018.33956

MACHADO, Márcia Buffon. (Trans)formação de professores em acoplamento com as tecnologias digitais. $2015.148 \mathrm{f}$.

Dissertação (Mestrado em Educação) - Programa de Pós-Graduação em Educação, Universidade de Caxias do Sul, Caxias do Sul, 2015. https://doi.org/10.18226/610001/mostraxvi.2016.45

MOROSINI, M. Estado de conhecimento e questões do campo científico. Revista da Educação, Santa Maria, v. 40, n. 1, p. 101-116, jan./abr. 2015.

MOROSINI, M. da C.; NASCIMENTO, L. M. do. Internacionalização da Educação Superior no Brasil. Educação em Revista, Belo Horizonte, n. 33, 2017. https://doi.org/10.1590/0102-4698155071

MUSSIO, Rogéria Albertinase Pincelli. A geração Z e suas respostas comportamental e emotiva nas redes sociais virtuais. 2017. 204 f. Dissertação (Mestrado em Desenvolvimento Humano e Tecnologias) - Instituto de Biociências de Rio Claro, Universidade

Estadual Paulista, Rio Claro, 2017.

NEJM, Rodrigo. Exposição de si e gerenciamento da privacidade de adolescentes nos contextos digitais. 2016.275 f. Tese (Doutorado em Psicologia) - Instituto de Psicologia, Universidade Federal da Bahia, Salvador, 2016. https://doi.org/10.20937/ rica.2017.33.02.01

OLIVEIRA, Inês Naves Cunha de. A construção de bandeiras: um cenário para exploração da geometria via tecnologia e interdisciplinaridade no Ensino Fundamental. 2019. 137 f. Dissertação (Mestrado em Matemática em Rede Nacional) - Instituto de Psicologia, Universidade Federal de Goiás, Catalão, 2019. https://doi.org/10.29289/259453942019v29s1ep69

OLIVEIRA, Marcos Bandeira de. O desenho no processo de criação e apresentação do projeto: o caso dos trabalhos finais de Graduação da Universidade De Fortaleza. 211 f. Dissertação (Mestrado em Arquitetura e Urbanismo) - Programa de Pós-Graduação em Arquitetura e Urbanismo, Universidade Presbiteriana Mackenzie, Fortaleza, 2015. https://doi.org/10.21041/conpat2019/ v2pat80

OLIVEIRA, Marcos Lopes de. Generalização de padrões e tecnologias digitais: estratégias didáticas para a aprendizagem. 2018. 141 f. Dissertação (Mestrado em Educação Matemática) - Programa de Estudos Pós-Graduados em Educação Matemática, Pontifícia Universidade Católica de São Paulo, São Paulo, 2018. https://doi.org/10.23925/1983-3156.2019vol21i3p419-437 
PAIS, J. M. Nas Rotas do Cotidiano. Revista Crítica de Ciências Sociais, n. 37, p. 105-115, jun. 1993.

PEREIRA, Ednaldo Coelho. Interação e relações interpessoais na ambiência de um sistema de educação presencial mediado por recursos tecnológicos. 2017. 213 f. Tese (Doutorado em Educação: Currículo) - Programa de Estudos Pós-Graduados em Educação: Currículo, Pontifícia Universidade Católica de São Paulo, São Paulo, 2017. https://doi.org/10.11606/d.48.2017.tde01112017-141239

SANTOS, Edméa. Mídias e tecnologias na educação presencial e a distância. [S. l.]: Grupo Gen-LTC, 2016. https://doi. org/10.11606/d.8.2017.tde-11122017-152049

SILVA, Sandra Regina. O ensino de Língua Estrangeira nas escolas públicas estaduais paulistas e as novas tecnologias. 2016. 108 f. Dissertação (Mestrado em Mídia e Tecnologia) - Faculdade de Arquitetura, Artes e Comunicação Universidade Estadual Paulista, Bauru, 2016.

STIEH, Daniela da Graça. Do pré-digital ao digital: o percurso das interações de professores em escola participante de programa de Inclusão Digital. 2015. 109 f. Dissertação (Mestrado em Educação) - Programa de Pós-Graduação em Educação, Universidade do Vale do Rio dos Sinos, São Leopoldo, 2015. https://doi.org/10.21041/conpat2019/v2pat80

TONATTO, Regiane Cristina. Este barco é nosso!: do ciberespaço aos caminhos rumo à alteridade. 2017. 149f. Dissertação (Mestrado em Sociedade, Cultura e Fronteiras) - Programa de Pós-graduação Stricto Sensu em Sociedade, Cultura e Fronteiras, Universidade Estadual do Oeste do Paraná, Campus de Foz do Iguaçu, 2017. https://doi.org/10.13102/asppdci.v1i13.4660

Recebido em: 1/12/2019.

Aprovado em: 20/12/2019.

Publicado em: 17/4/2020.

\section{Endereço para correspondência:}

Diana Leonhardt dos Santos

Pontifícia Universidade Católica do Rio Grande do Sul

Av. Ipiranga, 6681, prédios 8 e 9, sala 403 - Partenon

90619-900, Porto Alegre, RS, Brasil

\section{Autoras:}

Diana LeOnhardt dos Santos

Doutoranda em Educação pelo Programa de Pós-Graduação em Educação da Pontifícia Universidade Católica do Rio Grande do Sul (PUCRS), bolsista CAPES.

Orcid: https://orcid.or/0000-0002-0179-6106

E-mail: diana.santos@edu.pucrs.br 


\section{Karen Graziela Weber Machado}

Doutoranda em Educação pelo Programa de Pós-Graduação em Educação da Pontifícia Universidade Católica do Rio Grande do Sul (PUCRS),

bolsista CAPES.

Orcid: https://orcid.org/0000-0002-5115-8989

E-mail: karen.machado@edu.pucrs.br 